\title{
Challenges in obtaining consent for caesarean delivery in minors in South Africa
}

\author{
N C Ngene, ${ }^{1,2}$ MBBS, Dip Obstet (SA), Dip HIV Man (SA), MMed (Fam Med), FCOG (SA), MMed (Obstet Gynaecol), PhD; \\ T Bodiba, ${ }^{3}$ MB ChB, FCPaed (SA)
}

${ }^{1}$ Department of Obstetrics and Gynaecology, Klerksdorp Hospital, South Africa

${ }^{2}$ Department of Obstetrics and Gynaecology, School of Clinical Medicine, Faculty of Health Sciences, University of the Witwatersrand, Johannesburg, South Africa

${ }^{3}$ Department of Paediatrics, Klerksdorp Hospital, South Africa

Corresponding author: N C Ngene (ngenenc@gmail.com)

\begin{abstract}
A 16-year-old primigravida at term developed fetal compromise in the second stage of labour and had a delayed caesarean delivery (CD) because she declined the procedure after the medical manager had consented on her behalf following the unavailability of her parents. The baby that was delivered suffered neonatal encephalopathy. This report provides a recommendation on how to improve the process of obtaining consent for CD in minors in South Africa.

S Afr J Obstet Gynaecol 2020;26(1):38-41. https://doi.org/10.7196/SAJOG.2020.v26i1.1532
\end{abstract}

Caesarean delivery (CD) is a frequently performed obstetric procedure that requires consent. The elements of legal and ethical validity of the consent should include capacity, understanding, disclosure and voluntariness. These are crucial given that $\mathrm{CD}$ is associated with both short- and long-term complications. In SA, adults (individuals aged $\geq 18$ years) who are mentally competent may give consent to undergo surgical operation, while minors $<12$ years old cannot give consent. However, a minor aged $\geq 12$ years is required by the Children's Act No. 38 of 2005 to have the maturity and understanding to give consent to medical treatment, but may additionally consent to surgical operation if assisted by a parent or guardian. ${ }^{[1]}$ To preserve the life of a child in an urgent situation when there is no time to obtain the required consent, the medical superintendent or the representative of the superintendent can consent to a surgical operation being performed on a child. ${ }^{[2]}$ The law also provides that individuals who are $\geq 12, \geq 16$ and $\geq 18$ years old can consent to contraception, ${ }^{[3]}$ sexual activity ${ }^{[4]}$ and sterilisation, ${ }^{[5]}$ respectively. Additionally, a minor of any age can consent to termination of pregnancy (TOP). ${ }^{[6]}$ Nonetheless, attempts have been made to describe the assessment of patients' competence to consent to medical treatment. ${ }^{[7]}$ Unfortunately, the assessment is often complex and difficult. ${ }^{\left[{ }^{[8]}\right.}$

The current method of obtaining consent for $\mathrm{CD}$ in minors in many hospitals in South Africa (SA) is explained here. A pregnant minor who attends an antenatal clinic is assessed by a social worker to determine the circumstances surrounding the pregnancy and to provide her with social support. Before a non-emergency $\mathrm{CD}$, the parent/guardian of the minor provides consent while the patient assents to it before the procedure. In an emergency, the same is obtainable, but when the parent or guardian of the minor is not available, the hospital superintendent, usually represented by the medical manager or another clinician, provides consent before the $\mathrm{CD}$. If the minor refuses to assent, the following persons are usually invited to mediate and manage the situation: the parent, family member, midwife, social worker, medical manager and clinical psychologist (if available). This practice delays emergency CD and may be associated with poor pregnancy outcomes. Notably, the Children's Act in SA provides that the Minister of Health may give consent for treatment on a minor if the minor unreasonably refuses a medical or surgical procedure. ${ }^{[9]}$ In the case presented, the authors discuss this challenge and proffer practical solutions based on the context in SA.

\section{Case}

A 16-year-old primigravida who had normal antenatal care presented at a hospital in labour at 38 gestational weeks. On admission, the cervix was $2 \mathrm{~cm}$ dilated, and the fetal and maternal conditions were normal. At 24 hours after the onset of labour, the cervix was $5 \mathrm{~cm}$ dilated and the cardiotocography remained normal. After 4 hours, the cervix was fully dilated (second stage of labour). She developed fetal compromise (late decelerations and poor variability in the cardiotocograph) after an hour of monitoring during the second stage of labour, but instrumental vaginal delivery was contraindicated because the patient also had features of cephalopelvic disproportion. She was therefore booked for $\mathrm{CD}$. The patient was counselled, and she agreed to undergo $\mathrm{CD}$, but attempts to contact her parent/guardian to assist with the consent failed. Consequently, the medical manager provided consent for the $\mathrm{CD}$. Before transferring the patient from the labour ward to the operating theatre, she declined the $\mathrm{CD}$ and wanted to be given additional time for her baby to be delivered vaginally.

Following the refusal of the $\mathrm{CD}$, the patient was re-counselled repeatedly, and she eventually agreed to the procedure after 30 minutes of counselling. In the next 40 minutes, the patient had spinal anaesthesia and delivered a male baby with a birthweight of $3660 \mathrm{~g}$ and Apgar scores of 1 and 2 at 1 and 5 minutes, respectively. The delivery occurred at night. Umbilical artery blood gas at birth showed the following: $\mathrm{pH}$ 6.6; $\mathrm{pCO}_{2} 78 \mathrm{mmHg} ; \mathrm{pO}_{2} 19 \mathrm{mmHg}$; 
lactate $17.2 \mathrm{mmol} / \mathrm{L}$; and base excess and bicarbonate levels were incalculable. The baby was appropriately resuscitated at birth, admitted to the neonatal intensive care unit and diagnosed with neonatal encephalopathy. Post partum, the adolescent mother and her family were counselled. The clinical psychologist and social worker reviewed the adolescent mother. She was discharged home on the third day after the CD. However, the baby was discharged home after 4 weeks of hospital admission, and to be followed up in the outpatient clinic.

\section{Discussion}

Obtaining consent is a process, and one not preferably hastened; therefore, the discussion about the possibility of $\mathrm{CD}$ should start in the antenatal period. The second stage of labour is a momentous period when a parturient requires careful monitoring with the utmost support, and for a patient who has had antenatal care, it is less optimal to discuss consent for $\mathrm{CD}$ for the first time during this period. Therefore, antenatal care is of immense benefit.

During the first antenatal clinic visit, the contact details of the parent or guardian of each pregnant minor should be documented in the maternity case note. As illustrated in Fig. 1, each parent/guardian should visit the antenatal clinic, preferably accompanied by his/her ward (minor), to witness the assessment decision of the managing senior clinician on whether or not the child is of sufficient maturity to consent to procedures in that pregnancy. If the clinician's decision is contentious, the minor should be evaluated by a clinical psychologist to determine the patient's maturity to understand the recommended treatment, and ability to consent to surgical procedures. A neuropsychologist is often endorsed by legal counsel as the most suitable expert to assess the competence of a patient to consent to treatment. ${ }^{[8]}$ Therefore the involvement of a clinical psychologist is important, because $60 \%$ of mild to moderate cognitive impairments are undiagnosed and unrecognisable by family members. ${ }^{[8]}$ However, in many district

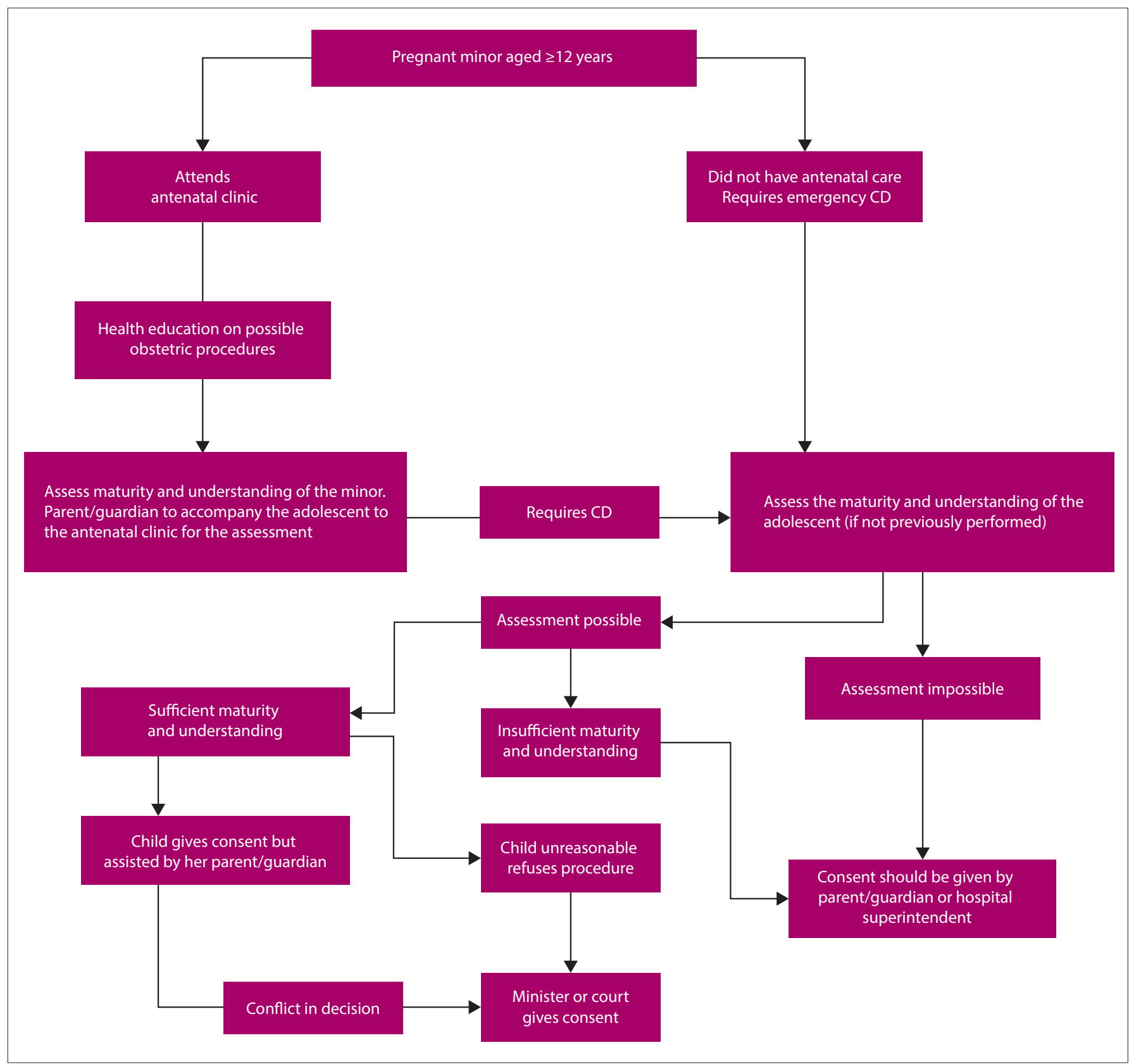

Fig 1. Overview of obtaining consent for $C D$ in minors. $(C D=$ caesarean delivery. $)$ 
hospitals and primary healthcare clinics in SA, a psychologist is a scarce resource, and may not be available. This entails that the minor should be assessed by both the clinician and the social worker who should be part of the standard antenatal care team for adolescents. If the minor is found to have sufficient maturity and understanding, the minor should subsequently give consent to each surgical procedure with assistance from her parent or guardian. Although this process may be elaborate, it will enhance confidence in the consenting process among minors, parents, clinicians and hospital managers. It may also prevent delays if an emergency procedure is required later. Additionally, it will prevent the dilemma that may emerge during the perioperative period of an emergency surgical procedure. In the case presented here, the medical officer on duty was overwhelmed at the time that the patient declined CD, because the same patient who could not give independent consent initially, declined the surgical procedure consented to on her behalf by the medical manager. This resulted in a loss of time, and consequently delayed the $\mathrm{CD}$. In fact, the Children's Act provides that the hospital superintendent can consent to a procedure on a child in an emergency situation where there is no time to obtain the required consent. ${ }^{[2]}$ In the index case, there was not enough time to obtain the required consent, therefore there was a strong case for the $\mathrm{CD}$ to be expedited. This is comparable to consent that may be given by the hospital superintendent where a parent refuses to consent to a life-saving treatment or surgical procedure in a child. ${ }^{[10]}$ Again, the Children's Act in SA provides that the Minister may give consent for treatment on a minor if the minor unreasonably refuses the medical or surgical procedure. ${ }^{[9]}$ Unfortunately, these aspects of the Act could not be invoked on the night of the incident because the staff on duty lacked clarity on the appropriate line of action.

When managing labour in a minor $\geq 12$ years of age who has not received antenatal care, an evaluation needs to be conducted to establish whether the minor has the maturity and understanding to consent to surgical procedures, including CD. During a lifethreatening emergency, the following persons may consent to a surgical procedure on a minor: (i) the parent/guardian, if the minor is unable to understand, ${ }^{[11,12]}$ (ii) the hospital superintendent, if there is insufficient time to obtain the required consent; ${ }^{[2]}$ and (iii) the Minister, if the minor refuses unreasonably. ${ }^{[9]}$ Administering a treatment without the child's consent will constitute a conflict between autonomy and beneficence, particularly given that the SA Constitution provides that every person has the right to bodily and psychological integrity. ${ }^{\text {[13] }}$ This approach may be contentious because of the fear that it can lead to post-traumatic stress disorder, may result in lack of trust of the minor in healthcare providers, and may lead to decreased efforts on the part of the clinician to get the necessary assent from the minor, which may constitute maleficence. The alternative approach of involving multiple team members to repeatedly counsel the patient carries a risk of delaying the procedure and may result in poor pregnancy outcomes. The fetus has no rights, but acquires such at birth as a newborn, ${ }^{[14]}$ and a permanent debilitating injury sustained is distressful to the family and places an enormous burden on the state's resources. To resolve the debate, a legal reform that also stipulates the timelines may be necessary. Again, a child of any age may consent to surgical TOP. It may also be argued that $\mathrm{CD}$ is akin to TOP, and children should be able to consent to $\mathrm{CD}$.

One further possibility is that an appeal may be made directly to the court on the basis that the clear pressing reality of a lifetime of hardship and suffering to both the fetus that is to be born and to be suffered by the minor is a concept clearly not recognised by the minor, and that the court must therefore act on the minor's behalf. This intervention may not be easily achieved at $02 \mathrm{~h} 00$.

The conflicts that may exist between ethics and law must be considered when acting in the best interest of the child. Therefore, national societal guidelines with explicit messages are required to assist clinicians - particularly those who encounter difficulty when obtaining consent for emergency treatment in children. The guidelines may assist in reducing the cost of litigation against healthcare practitioners who render live-saving and or harm-preventing emergency treatment/ surgical procedures to children. In Europe, for instance, the Ethics Working Group of the Confederation of European Specialists in Paediatrics has categorically stated: 'Where treatment is necessary to save a life or prevent serious harm, the doctor has the duty to act in the best interest of the child. ${ }^{[15]}$ This statement has been interpreted by the ethics committee of American Academy of Paediatrics to mean that a child may not refuse treatment for a life-threatening medical condition. ${ }^{[16]}$ When a parent unreasonably refuses to consent for the child's emergency treatment, the American Academy of Paediatrics recommends the involvement of a state child protective agency or the police to place the child under protective custody for administration of the treatment. ${ }^{[17]}$

\section{Conclusion}

To prevent delays and improve the process of obtaining consent for CD in minors, the authors recommend condemnation of statutory rape by all persons, prevention of unintended pregnancy, provision and utilisation of adolescents' clinics, ${ }^{[18]}$ efficient antenatal care and early involvement of parents/guardians in the consenting process, assessment by a social worker/clinical psychologist and good understanding of the applicable Acts. Additionally, information about consent in minors should be disseminated to the community to promote understanding and improve satisfaction after surgical procedures.

Declaration. The adolescent patient and her parent gave written informed consent for this case report to be published.

Acknowledgements. We are thankful to the following clinicians for providing useful advice during the drafting of the case report. Dr G Daef (Department of Obstetrics and Gynaecology, Klerksdorp Hospital, SA), Dr C O Onyia (Department of Psychiatry, Tshepong Hospital, SA) and Prof. J Moodley (Women's Health and HIV Research Group, Department of Obstetrics and Gynaecology, University of KwaZulu-Natal, Durban, SA).

Author contributions. NCN conceived the idea to report the case and drafted the manuscript. Both NCN and TB revised the manuscript and approved the final version.

Funding. None.

Conflicts of interest. None.

\footnotetext{
1. South Africa. Children's Act No. 38 of 2005. Section 129(2) and (3). https://www.justice.gov.za/ legislation/acts/2005-038\%20childrensact.pdf (accessed 20 April 2020).

2. South Africa. Children's Act No. 38 of 2005. Section 129(6). https://www.justice.gov.za/legislation/ acts/2005-038\%20childrensact.pdf (accessed 20 April 2020).

3. South Africa. Children's Act No. 38 of 2005. Section 134. https://www.justice.gov.za/legislation/ acts/2005-038\%20childrensact.pdf (accessed 20 April 2020).

4. South Africa. Criminal Law (Sexual Offences and Related Matters) Amendment Act No. 5 of 2015. Section 2. https://www.gov.za/sites/default/files/gcis_document/201507/3897777act5of2015criminallawa.pdf (accessed 20 April 2020).

5. South Africa. Sterilization Act No. 3 of 2005. Section 2(a). https://cisp.cachefly.net/assets/articles/ attachments/01958_sterilisationaa3.pdf (accessed 20 April 2020).

6. South Africa. Choice on Termination of Pregnancy Act No. 92 of 1996. Section 5(2) and (3) https://www.parliament.gov.za/storage/app/media/ProjectsAndEvents/womens_month_2015/ docs/Act92of1996.pdf (accessed 20 April 2020).
} 


\section{RESEARCH}

7. Barstow C, Shahan B, Robersts M. Evaluating medical decision-making capacity in practice. Am Fam Physician 2018;98(1):40-46.

8. Snow HA, Fleming BR. Consent, capacity and the right to say no. Med J Aust 2014;201(8):486-488. https://doi.org/10.5694/mja13.1090

9. South Africa. Children's Act No. 38 of 2005. Section 129(8). https://www.justice.gov.za/legislation/ acts/2005-038\%20childrensact.pdf (accessed 20 April 2020).

10. McQuoid-Mason DJ. What to do when a parent or guardian tries to override a legally competen child's consent to a surgical operation. S Afr Med J 2018:108(12):1030-1031. https://doi.org/10.7196/ SAMI.2018.v108i12.13492

11. McQuoid-Mason D. The National Health Act and refusal of consent to health services by children S Afr Med J 2006;96(6):530-532.

12. South Africa. Children's Act No. 38 of 2005. Section 129(5)b. https://www.justice.gov.za/legislation/ acts/2005-038\%20childrensact.pdf (accessed 20 April 2020)

13. South Africa. Constitution of the Republic of South Africa No. 108 of 1996. Section 12(2). https:// www.gov.za/sites/default/files/images/a108-96.pdf (accessed 21 April 2020).

14. Ngene NC. Refusal of antenatal care and the applicable conceptual models. Case Rep Wom Health 2019;22:e00110. https://doi.org/10.1016/j.crwh.2019.e00110
15. De Lourdes Levy M, Larcher V, Kurz R, Ethics Working Group of the Confederation of European Specialists in Paediatrics (CESP). Informed consent/assent in children. Statement of the Ethics Working Group of the Confederation of European Specialists in Paediatrics (CESP). Eur J Pediat 2003;162(9):629-633. https://doi.org/10.1007/s00431-003-1193-z

16. Katz AL, Webb SA, American Academy of Paediatrics Committee on Bioethics. Informed consent in decision-making in pediatric practice. Pediatrics 2016;138(2): e20161484. https://doi.org/10.1542/ peds.2016-1484

17. Committee on Pediatric Emergency Medicine and Committee on Bioethics. Consent for emergency medical services for children and adolescents. Pediatrics 2011;128(2):472-433. https://do. org/10.1542/peds.2011-1166

18. World Health Organization. Maternal, newborn, child and adolescent health: Adolescent responsive health systems. Geneva: WHO, 2020. https://www.who.int/maternal_child_adolescent/topics/ adolescence/health_services/en/ (accessed 27 August 2020).

Accepted 30 June 2020. 